\title{
Progress on Relationship between Natural Environment and Mental Health in China
}

\author{
Dongfang Zhu ${ }^{1,2}$, Linsheng Zhong ${ }^{1,2, *}$ and $\mathrm{Hu} \mathrm{Yu}{ }^{1}$ \\ 1 Institute of Geographic Sciences and Natural Resources Research, Chinese Academy of Sciences, \\ Beijing 100101, China; zdfashd@163.com (D.Z.); yuhu@igsnrr.ac.cn (H.Y.) \\ 2 College of Resources and Environment, University of Chinese Academy of Sciences, Beijing 100049, China \\ * Correspondence: zhlsheng@263.net
}

check for updates

Citation: Zhu, D.; Zhong, L.; Yu, H. Progress on Relationship between Natural Environment and Mental Health in China. Sustainability 2021, 13, 991. https://doi.org/10.3390/ su13020991

Received: 4 December 2020

Accepted: 15 January 2021

Published: 19 January 2021

Publisher's Note: MDPI stays neutral with regard to jurisdictional claims in published maps and institutional affiliations.

Copyright: (c) 2021 by the authors. Licensee MDPI, Basel, Switzerland. This article is an open access article distributed under the terms and conditions of the Creative Commons Attribution (CC BY) license (https:// creativecommons.org/licenses/by/ $4.0 /)$.

\begin{abstract}
Natural environment has a positive effect on individual mental health, which can be proved by many studies, both domestic and overseas. At present, some sunrise industries such as forest healthcare and natural tourism are booming in China. However, academically speaking, there's still a lack of systematic summary of researches on the relationship between natural environment and mental health in China, as well as a lack of comparison with foreign research achievements, which hinders the further development of the field to some extent in China. Therefore, this paper reviews the literature systematically by using the database, China National Knowledge Infrastructure (CNKI), in order to understand the research status in China and find out its gap with foreign studies. The results show that the study in this area in China can be divided into three stages, namely the embryonic stage (prior to 2000), the start-up stage (2001-2008) and the stage of initial development (since 2009); disciplines involved in the study mainly cover forestry, agriculture, psychology, medicine, sports science, tourism, ecology, education and geography. In general, the research in China concentrates on four topics: ecological psychology, the impact of natural ecological environment on mental health, the impact of artificial ecological environment on mental health, as well as the impact of natural tourism on mental health. Based on the findings, a future study framework and some main study lines are suggested: firstly, a systematic study on the relationship between natural environment and mental health in other countries should be conducted; secondly, factors affecting mental health in natural environment should be identified; thirdly, an evaluation system of psychological effect of natural environment should be established; finally, the utilization modes and influencing mechanism of natural environment should be explored.
\end{abstract}

Keywords: natural environment; mental health; research progress; prospect; China

\section{Introduction}

Mental health, as a good and continuous psychological state in the process of one's growth and development, includes normal intelligence, good mood, harmonious interpersonal relationship, adaptability to the environment and complete personality [1,2]. It is an important part of health, which is of great significance to the promotion of individual happiness as well as social harmony and stability. However, the health status of people around the world is not optimistic; it is estimated that about 1 in 10 people in the world has a mental health problem, and more than 10 million people globally attempt to commit suicide each year [3,4]. In China, about 200 million to 300 million people are subject to psychological problems; 16 million people are suffering from severe mental illness; about 70 percent people are in a state of "sub-health" [5]. All of these psychological problems and mental illnesses have become major obstacles for individual development and social stability. Therefore, it is very important to prevent and treat these psychological problems and mental diseases.

With the development of medical technology, a large variety of psychological counseling and psychotherapy methods are emerging, such as cognitive therapy, behavior cor- 
rection, hypnosis, group therapy, exercise therapy as well as naturopathic therapy [3]. Among them, naturopathic therapy based on natural environment has become increasingly popular in recent years with increasing popularity and acceptance. Actually, as early as in the 1950s, research on the influence of natural environment on mental health had already been conducted in foreign countries, and natural environment was believed to meet individual healing needs and be better for reducing stress, anxiety and depression [6]; meanwhile, a series of classical theories including the Arousal Theory, the Biophilia Hypothesis, the Savanna Hypothesis, the Attention Recovery Theory as well as the Stress Recovery Theory had been developed [7]. In China, after the reform and opening-up, the rapid urbanization and industrialization, along with the fast pace of production and lifestyle posed some negative impact on people's health, reducing a large number of people into a state of sub-health, with their demand for physical and mental health being constantly upgraded. In this context, some sunrise industries such as forest healthcare, natural tourism and horticulture have been booming in China. However, academically speaking, there's still a lack of systematic summary of researches on the relationship between natural environment and mental health in China, as well as a lack of comparison with related foreign research achievements, which hinders the further development of the field in China.

Therefore, in order to understand the research progress of this field in China, we collect the domestic literature on the relationship between natural environment and mental health systematically, and then analyze the main research topics, perspectives and methods; also, we compare the Chinese and international research in the area; finally, based on the analysis, a future research framework for this field in China is proposed. In general, this paper will contribute to the existing literature in the following ways. On one hand, based on the database of CNKI, the authors conduct a scientific literature analysis on this area in China, which illustrate the general situation in this field, evaluate the gap between China and the world, and also form a knowledge system and lay a preliminary foundation for the future research. On the other hand, as the developing country, Chinese people are becoming more and more interested in health and looking forward to achieve health recovery through travel, vacation and other leisure ways; in this context, this paper puts forward the further research framework on this field mainly from the perspectives of tourism and geography, in order to make more deeply aware of the various roles, complexity and spatial differentiation between natural environment and mental health. Besides, this paper will offer some reasonable insights into a more characteristic research direction in the future, to support the deepening, China's Ecological Civilization and provide some experiences for other countries.

\section{Literature Overview}

\subsection{Literature Collection}

China National Knowledge Infrastructure (CNKI) is the world's largest Chinese knowledge portal, and also an important participant and witness in the development of digital libraries in China. With CNKI as the basic database, the authors searched for literature by using "natural environment and mental health", "forest and mental health", "grassland and mental health", "landscape and mental health", "gardening and mental health", "plants and mental health", "park and mental health", "green space and mental health" and "coast and mental health" as themes respectively, with the time of publishing and updating set as "unlimited". As a result, a total of 742 papers and articles were collected. Then we set the criteria of inclusion/exclusion as follows: (1) Repetitive and uncorrelated literature was excluded; (2) newspapers, conferences, yearbooks and books were excluded, but only academic journals and dissertations were retained. Finally, 119 sample articles of high relevance to the research became available, including 95 periodical papers and 24 master's thesis and doctoral dissertations. The process of sample literature collection is shown in Figure 1. 


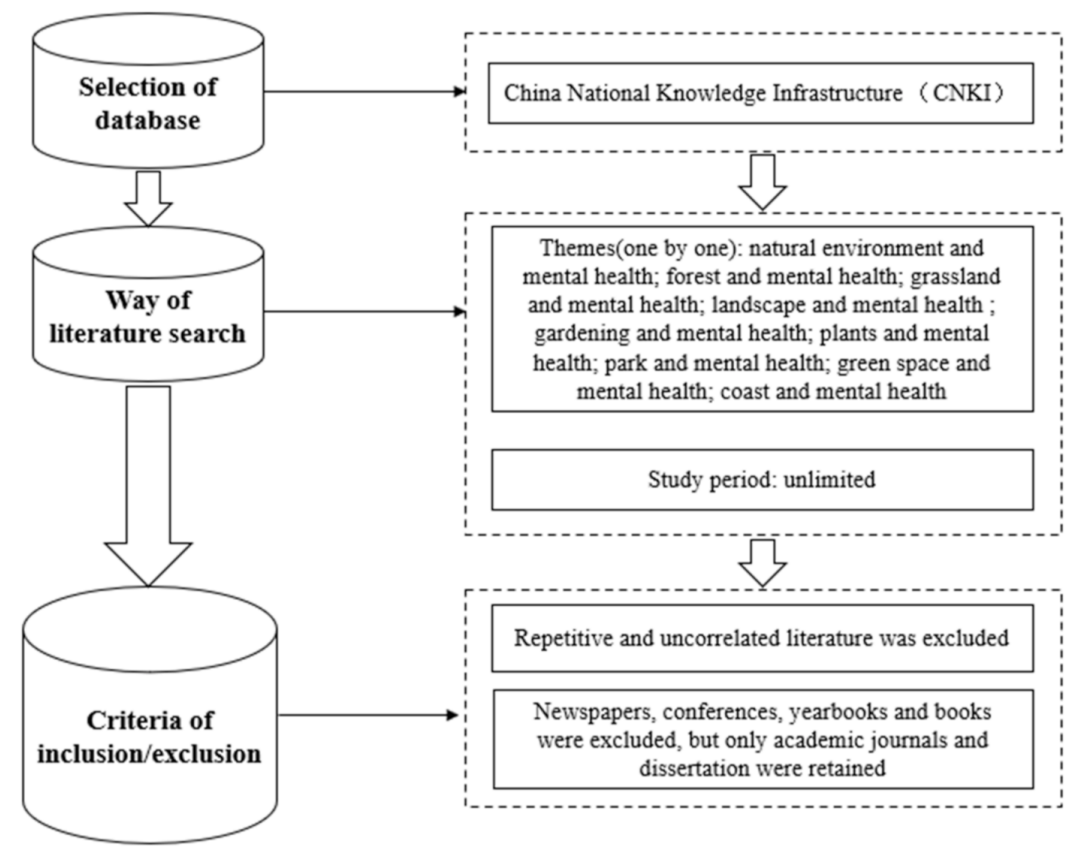

Figure 1. The process of literature collection.

\subsection{Research Process}

Through statistical analysis on the 119 sample articles, the paper drew up a diagram of the literature distribution by year (Figure 2). The result showed that research in China regarding the relationship between natural environment and mental health started from the 1990s, and developed through three stages in general.

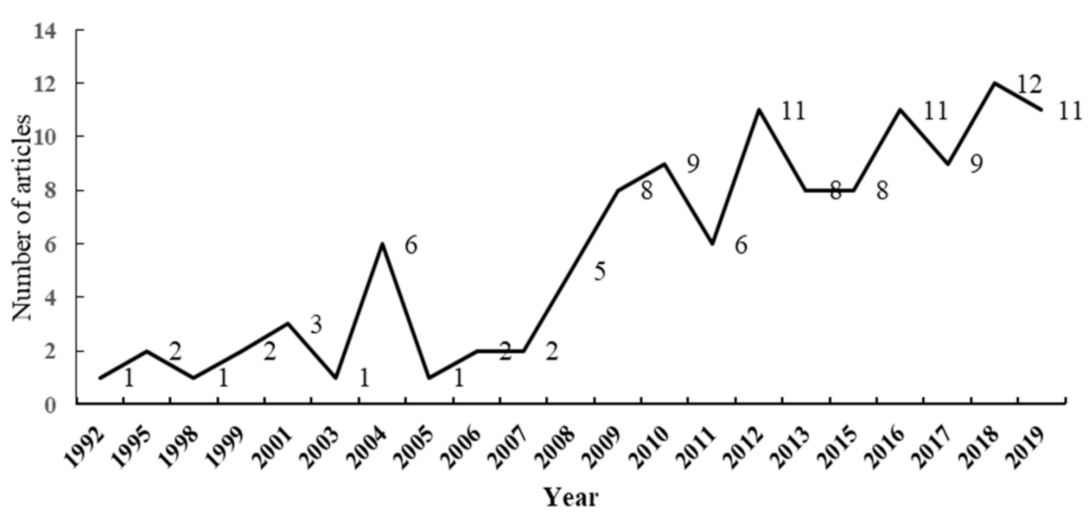

Figure 2. The annual distribution of literature on the relationship between natural environment and mental health in China.

(1) The embryonic stage (prior to 2000). In the 1990s, the effect of natural environment on mental health began to attract attention of Chinese scholars, nearly sixty years later than in foreign countries. Research at this stage in China was featured by limited achievements and simple perspectives and methods. Only six articles were available, focusing on meaning of forest bathing, its underlying mechanism in mental health and empirical research on forest bathing in schizophrenia therapy. As for research methods, qualitative methods were mainly used at this stage.

(2) The start-up stage (2001-2008). The prevalence of mental health problems increasingly attracted close attention of countries worldwide. At this stage, Chinese research on the relationship between natural environment and mental health was expanded in both achievements and perspectives, and a total of 20 articles were available. Chinese scholars started to pay attention to research on the impact of natural landscape such as forests 
and oceans and artificial ecological environment such as gardens, gardening and urban green space on mental health. In terms of research methods, quantitative research such as questionnaires and mathematical modeling started to emerge, but qualitative research remained predominant at this stage.

(3) The stage of initial development (since 2009). At this stage, the number of articles in the field kept increasing and nine articles became available annually on average. Several factors were associated with these achievements. For example, with the improvement of the living standards, Chinese people paid more and more attention to health; besides, the intensified pressure on urban residents steered a large number of people towards nature for escape from daily life and work. Hence, the role of nature tourism, outdoor sports, urban green space and other natural elements in mental health came into the academic view. In this phase, the research topics were extended to the mechanism and empirical research on the effects of underlying elements of natural environment on mental health. Meanwhile, some new quantitative methods such as structural equation modeling, experimental method and regression modeling emerged one after another.

\subsection{Research Fields}

Statistical analysis of the sample literature showed that the disciplines engaged in the research on the relationship between natural environment and mental health in China were mainly forestry (landscape architecture), agronomy (horticulture), psychology, medicine, sports science, tourism, ecology, education and geography. As for the 119 sample articles, the 95 periodical papers were published in over 60 periodicals (Table 1), with the majority published in forestry, agronomy and medicine periodicals; the 24 Master's Thesis and doctoral dissertations were mainly focused in forestry and tourism, among which Beijing Forestry University, Northwest Agriculture and Forestry University and Chinese Academy of Forestry were the three universities and research institutes that published most.

Table 1. Distribution of research results in journals on the relationship between natural environment and mental health in China.

\begin{tabular}{|c|c|c|c|}
\hline Type of Periodical & Number of Papers & $\begin{array}{l}\text { Percentage } \\
\text { (95 in Total) }\end{array}$ & Subject of Research \\
\hline Forestry & 41 & $43.2 \%$ & $\begin{array}{l}\text { Health mechanism of forests and } \\
\text { gardens, and their impact on } \\
\text { mental health }\end{array}$ \\
\hline Agronomy & 16 & $16.8 \%$ & $\begin{array}{l}\text { Impact of green space on mental } \\
\text { health and horticultural therapy }\end{array}$ \\
\hline Medicine & 13 & $13.7 \%$ & $\begin{array}{l}\text { Healing gardens, horticultural } \\
\text { therapy and natural impact factors } \\
\text { for mental health improvement }\end{array}$ \\
\hline Psychology & 6 & $6.3 \%$ & $\begin{array}{l}\text { Relationship between close contact } \\
\text { with nature and mental health, } \\
\text { ecological psychology, etc. }\end{array}$ \\
\hline Sports science & 4 & $4.2 \%$ & $\begin{array}{l}\text { Outdoor experience for mental } \\
\text { health improvement }\end{array}$ \\
\hline Tourism & 4 & $4.2 \%$ & $\begin{array}{c}\text { Forest healthcare tourism, tourism } \\
\text { activities and mental health } \\
\text { of tourists }\end{array}$ \\
\hline Ecology & 3 & $3.1 \%$ & $\begin{array}{l}\text { Green space and residents' mental } \\
\text { health, marine ecological health and } \\
\text { mental health }\end{array}$ \\
\hline Education & 1 & $1.1 \%$ & Psychological tourism \\
\hline Geography & 1 & $1.1 \%$ & $\begin{array}{l}\text { Study on stress relief and recovery of } \\
\text { fatigue in urban natural environment }\end{array}$ \\
\hline Others & 6 & $6.3 \%$ & $\begin{array}{l}\text { Healing gardens, restorative } \\
\text { environment, etc. }\end{array}$ \\
\hline
\end{tabular}




\subsection{Methods Used in the Literature}

Based on the sample literature, we found that in the domestic research on the relationship between natural environment and mental health, quantitative research accounted for about $48.7 \%$ and qualitative research for about $51.3 \%$. Among the quantitative research, questionnaires and experimental methods were the main methods used, contributing to $50.0 \%$ and $34.5 \%$ respectively; structural equation modeling, regression modeling and other mathematical modeling were also important quantitative methods, which were mostly used in research on changes with mental health level of different social groups after contact with natural environment, as well as in research on impact of forest healthcare tourism on stress relief. Among the qualitative research, induction, literature analysis and interviews were the main methods, accounting for $60.7 \%, 26.2 \%$ and $13.1 \%$ respectively, and they were mainly used in research on the underlying mechanism of natural environment elements such as forests and gardens for mental health promotion, related literature review and the participants' perception of mental health status (Table 2).

Table 2. Main research methods used in the research on the relationship between natural environment and mental health in China.

\begin{tabular}{|c|c|c|c|}
\hline \multicolumn{2}{|c|}{ Research Methods } & Research Topics & $\begin{array}{c}\text { Representative } \\
\text { Authors }\end{array}$ \\
\hline \multirow{3}{*}{ Qualitative } & Induction & $\begin{array}{l}\text { Positive effect of nature } \\
\text { on human, forest bathing, } \\
\text { ecological psychology, } \\
\text { etc. }\end{array}$ & $\begin{array}{c}\text { Zhang, 1995; Xiao, } \\
\text { 2004; He, } 2016 \text { [8-10] }\end{array}$ \\
\hline & Literature analysis & $\begin{array}{l}\text { Research progress in } \\
\text { forest healthcare, } \\
\text { psychological well-being } \\
\text { in urban green space, } \\
\text { psychological well-being } \\
\text { in parks, etc. }\end{array}$ & $\begin{array}{c}\mathrm{Hu}, 2012 \text {; Shu et al., } \\
\text { 2018; Wen et al., } 2012 \\
\text { [11-13] }\end{array}$ \\
\hline & Interview & $\begin{array}{l}\text { Ecological environment } \\
\text { and mental state of } \\
\text { citizens, tourists' } \\
\text { behavior and pressure } \\
\text { transfer }\end{array}$ & $\begin{array}{c}\text { Wang, 2009; Ma et al., } \\
2010[14,15]\end{array}$ \\
\hline \multirow{5}{*}{ Quantitative } & Questionnaire & $\begin{array}{l}\text { Empirical research on the } \\
\text { effect of nature on mental } \\
\text { health }\end{array}$ & $\begin{array}{c}\text { Wang, 2012; } \\
\text { Chen et al., } 2017 \\
{[16,17]}\end{array}$ \\
\hline & Experiment & $\begin{array}{l}\text { Empirical research on the } \\
\text { impact of nature on } \\
\text { mental health }\end{array}$ & $\begin{array}{c}\text { Wang, 2018; Liu, } 2019 \\
\text { [18,19] }\end{array}$ \\
\hline & $\begin{array}{l}\text { Structural equation } \\
\text { modeling }\end{array}$ & $\begin{array}{l}\text { Perception research on } \\
\text { forest healthcare tourism }\end{array}$ & $\begin{array}{l}\text { Zheng et al., 2017; } \\
\text { Mo, } 2019[20,21]\end{array}$ \\
\hline & $\begin{array}{l}\text { Regression } \\
\text { modeling }\end{array}$ & $\begin{array}{l}\text { Benefit of urban green } \\
\text { space for residents' } \\
\text { health, impact of urban } \\
\text { park on people's health }\end{array}$ & $\begin{array}{c}\text { Tan et al., 2018; } \\
\text { Zhang, } 2019[7,22]\end{array}$ \\
\hline & $\begin{array}{l}\text { Mathematical } \\
\text { modeling }\end{array}$ & $\begin{array}{l}\text { Evaluation research on } \\
\text { urban forest healthcare }\end{array}$ & Han, 2011 [23] \\
\hline
\end{tabular}

\section{Research Topics}

After analyzing the contents of the sample literature, we summarized that the domestic research on the relationships between natural environment and mental health mainly into four fields, namely ecological psychology, impact of natural ecological environment on 
mental health, impact of artificial ecological environment on mental health and impact of nature tourism on mental health.

\subsection{Ecological Psychology: Theory Development on the Effect of Natural Environment on Mental Health}

Absence of nature for human (namely separation of human and nature) is the natural root of various mental health problems that occur frequently in the modern society [24]. Ecological psychology, which originates from the alienation of human from nature, attempts to restore the bond between human and nature, as well as stimulate human to return to nature; furthermore, it highlights the psychological value of natural ecological environment, and resorts to the restorative property of nature to promote physical and mental development and cure psychological and mental diseases [15]. Though ecological psychology is a branch of psychology proposed by Roger Barker in the 1940s-1970s, academic consensus has not been reached on its concept and research object currently in China, yet what is universally recognized is the ecological psychology in dichotomy. One is "ecological psychology of ecology", which attempts to apply theories and methods in ecology into psychology and highlights the ecologization of psychology. The other is "ecological psychology of ecological crisis", which targets environmental problems and stresses the importance of re-examining ecological environment crisis from the perspective of psychology seeking the underlying causes of ecological environment problems [25]. Currently in China, quite a few scholars believe that ecological psychology includes ecological psychology in the narrow sense and that in the broad sense, with the former referring to the ecologization trend of psychological research and the latter including both the former and ecological psychology paying close attention to ecological crisis [26,27].

Psychological value of natural environment for human is one of the major subjects in ecological psychology research, and it mainly includes developmental, healing, spiritual and self-fulfilling value [28]. Domestic scholars kept conducting empirical research to verify such psychological value. For instance, Ma et al. devised a mental adjustment tests of citizens in Yamalike Mountain and demonstrated in results that natural environment had significantly positive influence on mental adjustment ability of human [29]. Based on the surveys on contact of youths with nature in Zhuhai, Chen et al. believed that close contact with nature of youths in Zhuhai could reduce problems with their conduct, hyperactivity and attention, and enhance their peer interaction [17]. Generally, on the basis of the psychological value of natural environment, many scholars came up with various ecological therapies such as wilderness therapy, natural environment therapy, outdoor therapy, forest therapy and horticultural therapy $[9,16,30]$.

\subsection{Research on the Impact of Natural Ecological Environment on Mental Health}

3.2.1. Impact of Forest Environment on Mental Health

(1) Health Factors

In the forest environment are many health factors helpful for physical and mental development. These factors play an important role in relieving mental stress and promoting mental health; therefore, the forests environment attract widest attention in the domestic research.

The first health factor is the particular climate environment in the forest. The special underlying surface conditions bring forest areas a special climate, namely, forest climate. The forest climate is featured by less solar radiation, vertical distribution of light intensity, limited daily and annual temperature range, high humidity and low wind velocity. Such pleasant climate environment helps regulate human nervous system, improve respiratory and digestive functions, enhance human immunity, bring physical and mental comfort, and ease stress [31]. The second health factor is aero-anion. The aero-anion has many functions, such as sterilizing and reducing dust, cleaning air, improving immunity, enhancing cardiopulmonary function, adjusting the central nervous system, improving sleep, easing stress and anxiety, as well as relieving fatigue [11,32], earning it the popular name 
as air vitamin and longevity factor. In the forests, the aero-anion concentration can reach as high as $10,000 / \mathrm{m}^{3}$, which is 50 times that in street shade areas and 200 times that in cities [33]. The third health factor is phytoncidere. In fact, forest plants generally release massive volatile substances, namely, phytoncidere. The volatiles, which are usually of high physiological activity [34], play an important role in many ways such as sterilizing, anti-inflammatory and anti-cancer, and are also helpful for relieving fatigue, easing tension, bringing pleasure, stabilizing mood and refreshing mind [35]. The fourth health factor is the acoustic environment in forests. Forests exert an important effect of noise reduction and woods in a large area can reduce noise by 26-34 decibels [36]. So, as a "natural silencer", forests can create a quiet local environment, reduce restlessness of human and bring pleasure in mind [37]. Usually, in forests are various sound elements such as sounds of animals, water, wind and rain, and these harmonious sounds enter human body via hearing organs and mind, producing resonance reactions with cells in the body, which is helpful for easing fatigue and nervousness [38]. Finally, the fifth health factor is forest landscape, which mainly consists of plants, flowers and grass of different colors and clear water. Green is the keynote of forest landscape, and the high "green looking ratio" makes people peaceful, relaxed and comfortable, thus creating a sound mental state [10]. Generally, these five health factors of the forest environment jointly work on the nervous system of human body and exert combined effect to promote improvement of mental activities and health level.

(2) Influential Effect

As a restorative environment, forest environment as well as the forest-related activities exerts significant effect on relieving stress of human, which has been verified by quite a few empirical studies in China. For instance, based on Attention Restoration Theory and Stress Relief Theory, Zhu, Zheng et al., and Mo constructed the forest tour experience scale, perceived effect scale and restorative experience scale, and then discussed the effect of forest tour activities for easing stress of visitors and adjusting the sub-mental health state. In conclusion, they believed the forest environment played a promoting role in stress relief [20,21,39]. Besides, forests were also important for easing anxiety and improving state of mind [40]. Based on Self-Rating Anxiety Scale (SAS), Zhang et al. studied the change of anxiety status of visitors before and after visiting Jingshan Forest Park in Jiangxi, and found that forest environment was effective in relieving symptoms in the anxiety scale [41]. Furthermore, several factors were found to contribute to the adjustment effect of forest environment for human mental state, and these factors mainly included visit frequency, duration of stay, and structural types of forests; generally speaking, 1-2 visits monthly, duration for more than two hours in the forest environment and the semi-closed forests were optimal $[19,42]$. Besides, Hao et al. found that varied types of sound in forests had different influence on human mental state, with sound of birds, flowing water and wind stirring leaves better striking a chord with human body and enhancing pleasure [43]; this was related to multiple factors such as type of sound source, frequency, loudness, timbre, area of space, visual landscape and evaluation entity [24]. Finally, as the embodiment of the combined effect of forest environment, forest bathing plays an important role in the schizophrenia treatment. For instance, Li et al. divided the 848 schizophrenic patients into two groups, the forest bathing group and the group of closed-off management with chlorpromazine, and found that forest bathing showed significant effect for all the schizophrenic patients [44].

(3) Regulatory Measures

In view of the psychological value of forest environment for easing stress, improving mind state and treating schizophrenia, the relevant planning and design of forest bathing places and forest health resorts have become popular. Since forest bathing was introduced into China in the 1990s, scholars started to discuss its healthcare value both physiologically and mentally [8,45]. Meanwhile, along with the development of forest therapy and the "great health industry" in China, the site selection, product design and the auxiliary facilities for forest bathing places became the main research topics. It was admirable to locate the 
forest bathing places in forests $20-50 \mathrm{~km}$ away from large and medium-sized cities and more than $20 \mathrm{~km}$ away from industrial and mining areas or downtown areas, with mild topographic relief, slope of no greater than $20^{\circ}$ and clean drinking water and flowing water; besides, the forests which could develop into forest bathing places should enjoy high forest coverage, rich varieties of trees and high air cleanliness [46,47]. In addition, both hardware facilities and software facilities should be considered when developing forest bathing places and forest health resorts. Development of the hardware facilities generally included selection of tree varieties, design of walkways, rest stops, signage system, fountain facilities, water (medicated) bathing places, amusement and entertainment areas, accommodation facilities, catering service, safety facilities as well as medical facilities [35,47]; development of the software facilities was mainly about design of forest convalescence products and activities, such as forest music, forest dance, forest painting, forest catharsis activities and healthy catering [48].

\subsubsection{Impact of Coastal Environment on Mental Health}

Coastal areas, with scenic natural landscapes and favorable convalescence conditions, have become important natural places for relaxing body and releasing pressure. Coast, as an important ecosystem on earth, is a major choice for people to conduct outdoor activities, experience nature and promote mental health [49]. Generally, the comprehensive convalescent factors in the coastal environment such as sunbath, sea bath, air bath and sand bath could eliminate ambivalence and nervousness of the retired military convalescents, ease their depression and improve their mental state [50]. In China, there are several famous tourism destinations, such as Sanya city. Sanya city is a famous health tourism destination in China because of its high air quality, sound sunshine conditions and favorable beach environment, as well as its comprehensive convalescent factors such as sunbath, air bath and sea bath; these factors could significantly relieve anxiety, agitation and melancholy of the convalescents at Sanya Sanatorium [51]. Although the coastal environment plays a vital role for people's mental health, Chinese research in this field presently remains limited compared to its function on people's physical health, and only three related articles are available.

\subsection{Research on the Impact of Artificial Ecological Environment on Mental Health 3.3.1. Impact of Urban Green Space on Mental Health}

Green space, as an integral part of urban ecosystem, not only plays an important role physically in adjusting temperature and humidity, reducing noise, breaking wind and fixing sand, and improving urban microclimate, but also is increasingly recognized and verified in its psychological wellbeing benefit. Urban green space was a typical open green natural environment and performed healthcare functions by evoking human's natural attributes, improving the living environment conditions, stimulating the five senses of human body and providing activity support for human [52]. Furthermore, the urban green space could effectively ease mental stress and anxiety, bring comfort, adjust negative emotions, and thus improve urban residents' mental health state [12]. Urban green space also offered places of recreation, activities and exercises to urban residents, and these exercises and social activities played a promoting role for the residents' mental health [53]. Among urban residents, different social groups perceived the mental health benefit of green space differently, with the elderly, the highly educated and the females better recognizing its benefits [7]. The mental health benefit was also related to such factors as frequency of green space use by residents, quantity of green space, as well as their quality and sanitary conditions. In general, higher frequency of use indicated better mental health state of residents [54]; better conditions of green space environment generated higher life quality as perceived by residents and stronger positive emotions [6]. Therefore, close attention was paid to the design of urban green space. For example, Ying proposed the health design methods including green planting, color environment, health-preserving plants 
and ecological space for the accessory green space of medical institutions as well as the residential green space [55].

\subsubsection{Impact of Garden Landscape on Mental Health}

Plants are the main expressions and also the main materials of garden landscape, and the garden landscape consisting of plants as the predominant part is diversified. Domestic scholars studied the psychological impact of garden landscape on human mainly from the perspectives of shape, color and odor. In general, the plants could be generally divided by shape into the natural plant landscape and the geometric plant landscape (artificial landscape with regular patterns after artificial trimming). Research based on the emotion scales demonstrated that the natural plant landscape better eased tension and promoted positive emotions than the artificial plant landscape [56]; the indicator of electroencephalogram (EEG) change showed that the broad-leaved forests had greater positive impact on human's mental state than the conifer-broadleaf forests and coniferous forests [57]. Here was an interesting finding. The shape of peonies posed different psychological influence on human at different stages, including leaf expansion, initial flowering, peak flowering and late flowering. The three psychological indicators of the body, namely fatigue, anger and depression recorded the lowest value during the stage of peak flowering, which indicated that peonies during peak flowering could best relieve body fatigue, depression and other negative emotions [58]. Moreover, the garden plants of different colors had different effects in improving mood and adjusting emotions. Specifically speaking, green plants improved mental health best, including recovery from negative emotions such as tension, depression and fluster [18]; red and yellow plants brought people positive emotions such as joy and excitement; purple plants could effectively promote human body to relax and reduce anxiety, fatigue and anger; pink, white and blue plants could lower the level of body vitality [37,59]. As for plant odor, the related research concentrated on the aromatic plants. Aromatic plants were the collective name for the plants containing essential oil, volatile oil and nonvolatile gum, and mainly included four types, namely aromatic wood plants, aromatic grass plants, aromatic flower plants and aromatic fruit plants [60]. Besides the functions of air purification, sterilization and disinfection, the aromatic plants could help eliminate fatigue, ease stress, and relieve anxiety and depression [61]. For instances, the aroma of mint could stimulate imagination; the aroma of rose could trigger delight; and the aroma of lavender could ease anxiety [62]. Because of the healthcare function of the aromatic plants, aromatherapy was continuously applied to the treatment of mental diseases, cancer and delivery currently [63]. There were some important factors affecting the psychological effect of garden landscape, gender being one of them, but the research conclusions in China were inconsistent. For instances, with EEG change as a psychological evaluation indicator, the result of study by Kang et al. suggested that the plant landscape posed a greater effect of stabilizing emotions among males than females [64], but Liu et al. held that physical tension of females was eased in mountain forest and wetland landscape to a better effect than males [65].

\subsubsection{Impact of Gardening Activities on Mental Health}

Horticultural therapy was mainly used in the United States after the Second World War to treat psychological trauma of soldiers after war, and it referred to an effective method of improving physical and mental state with plant cultivation and gardening activities $[66,67]$. Generally speaking, horticultural therapy mainly used plant color, plant aroma, plant diet and gardening activities to work on and adjust human body through sight, taste, smell, hearing and touch [68]. As horticultural therapy was functional in relieving pressure, improving mental state and enhancing social skills, it was currently used mainly as an adjunctive therapy in prevention and treatment of physical and mental diseases of the senile, the young, patients with mental diseases, the retarded, the disabled and socially vulnerable groups [69]. 
At present, gardening activities are widely used in treating mental diseases in China. For example, gardening activities could effectively reduce loneliness, flinch, delusion and hallucination of the schizophrenic patients, help recover the brain functions, arouse the patients' interest in life and help improve their self-care ability in daily life and social adaptability [70-72]. Combination of gardening activities and healing gardens also showed some effect in psychological intervention with autistic children $[7,73,74]$. Besides, in the process of mental disease treatment and sub-health improvement, horticultural therapy could ease anxiety of the hospitalized mental disease patients [75], reduce alienation of the middle school students [76], and alleviate the negative emotions of the college students such as inferiority, anxiety and depression as well as eliminate their tension and anxiety $[77,78]$. Meanwhile, gardening activities brought pleasure to $80 \%$ of the elderly [79], and also helped with the psychological rehabilitation of the earthquake victims [80].

\subsection{Research on the Impact of Nature Tourism on Mental Health}

Nature tourism was a type of tourism based on natural environment and natural resources out of the intrinsic human need of contact with nature [81]. In the process of nature tourism, sightseeing, mountain climbing, drifting and other activities brought human body into full contact with nature and could ease tension and fatigue, and thus significantly alleviate anxiety of the tourists $[3,82,83]$. In general, nature tourism played a mediating role in pressure perception and pressure transfer of tourists and was significantly effective in adjusting spiritual life and easing pressure of employees $[14,84,85]$. Given the positive effect of nature tourism on human's mental health, Lushan Mountain in Jiangxi province, Hangzhou in Zhejiang province, Huangshan Mountain in Anhui province, Songshan Mountain in Henan province and many other tourist scenic spots in China have developed many health tourism projects as represented by forest bathing, sun bath, sea bath, hot spring bath, medicated diet, Qigong, healthcare exercise, Tai Chi and Five-Animal Exercise [86]. Moreover, a few scholars proposed the concept of "psychological tourism" [87], which believed that the professional psychological counseling and therapy during tourist activities could promote mental health of the participants [88]. However, research on "psychological tourism" currently only dwells on the proposal of concept and summarization of psychological effect, without support from empirical research.

\section{Discussion and Conclusions}

As mental health problems are getting popularized, research in China on the relationship between natural environment and mental health exhibits the trend of growing in recent years, with the following characteristics in general.

(1) Chinese research on the relationship between natural environment and mental health started in the 1990s, nearly sixty fifty years later than that in foreign countries; during 2001-2008, with the increasing mental problems emerging in China, more and more scholars engaged in this research; after 2009, as the health awareness of Chinese people was rising and the pressure for urban residents was intensified, the academic research in this field became increasingly popular. The research in China mainly concentrates on the progress of related research overseas and the localized application of overseas Arousal Theory, Attention Restoration Theory and Pressure Recovery Theory as well as some empirical studies, the theoretical innovation is insufficient. Moreover, regarding the natural elements, though the research focuses on discussing the relationship between forests, garden landscape, gardening activities and nature tourism and mental health, with some results already yielded, yet the analysis is mostly confined to one natural factor and its psychological effect, with the comprehensive research on psychological effect of natural environment remaining to be conducted. In other countries, however, apart from focusing on the positive effect of natural environment on mental health $\mathrm{m}$, greater attention is paid to the influencing mechanism underlying the mental health promotion of natural environment [92-94], the comparison among different types of natural environment on their effect on mental health $[95,96]$, in both macroscopical scales and 
microcosmic scales (the research in China is mainly in microcosmic scales) [97,98], as well as the relevant theoretical studies $[99,100]$. Besides, some of the foreign studies believed that certain natural environment may have negative effects on mental health of some individuals. For example, Milligan and Bingley found that although woodland could calm some participants, it created anxiety and uncertainty for the others [101].

(2) Effect evaluation of natural environment on mental health is an important part of research in the area both inside and outside China. Chinese research on mental wellbeing benefit of natural environment remains under initial development, without a wellestablished evaluation system. In general, two method systems, subjective evaluation and objective evaluation, have been preliminarily developed (Table 3). To be specific, subjective evaluation, based on psychological testing, mainly describes the perception of respondents in the process of experiments and generally uses scales and questionnaires to measure the mental state of respondents and its changes. Scales commonly used include Profile of Mood States (POMS), Self-Rating Anxiety Scale (SAS), Positive and Negative Affect Scale (PANAS) and State-Trait Anxiety Inventory (STAI), which are also widely used globally [102,103]. For instance, Marselle et al. adopted Perceived Stress Scale and Positive and Negative Affect Schedule to compare the mental well-being benefit of walking in natural environments with that in urban environments [104]. Objective evaluation in China usually uses electronic instruments to measure physiological indices of respondents such as EEG, heart rate, respiratory rate and skin conductance response, which reflect the changes with mental state of the respondents. Moreover, the major data sources of the two kinds of evaluation in China is the primary data on the participants, while the data source in other countries are relatively diverse, such as use of smartphones [105], data from centers for disease control or similar departments [97] and national projects [106]. Furthermore, Chinese researchers mainly use either subjective or objective method, lacking research with the methods combined, and under the impact of experimental apparatus, evaluation indices and evaluation standards, comparability among result of researches is not high [107]; while foreign research usually combines the two [108], being more comparable and scientifical in conclusions.

(3) The research on the relationship between natural environment and mental health in China is conducted mainly by scholars in different fields, who have conducted the studies from different perspectives based on their own specialty, leading to results that are rather scattered and less systematic. On the whole, the academic groups engaged in this field are rather diversified, covering multiple disciplines including forestry, agronomy, medicine, psychology, sports science, tourism, ecology, education and geography, among which forestry plays a dominant role in the academic community. In comparison, it' quite different in the international academic community, where environmental sciences and health sciences pay more attention to this research. As for the research methods, the qualitative methods such as induction and literature analysis have been widely applied in China, and, the quantitative methods represented by questionnaires and experimental methods are used into related empirical research. In recent years, some quantitative methods such as structural equation models, regression models and other mathematical modeling start to emerge. They support the research to evolve from simple qualitative analysis to semiquantitative and quantitative cross-over research, thus deepening the data analysis and improving the variable explanation ability on the key topics.

Table 3. Main evaluation index of psychological effects of natural environment on mental health in China.

\begin{tabular}{ccc}
\hline Method of Evaluation & Way of Evaluation & Content \\
\hline Subjective evaluation & Semantic differential (SD) & $\begin{array}{c}\text { Respondents choose a scale of } \\
\text { words and use multiple pairs } \\
\text { of adjectives to indicate } \\
\text { their feelings. }\end{array}$ \\
\hline
\end{tabular}


Table 3. Cont.

\begin{tabular}{|c|c|c|}
\hline Method of Evaluation & Way of Evaluation & Content \\
\hline & Profile of mood states (POMS) & $\begin{array}{l}\text { Calculation of POMS index: } \\
\text { Total score of } 5 \text { negative mood } \\
\text { states (tension, anger, fatigue, } \\
\text { depression, confusion) minus } \\
\text { score of } 2 \text { positive mood states } \\
\text { (vigor, friendliness), and then } \\
\text { plus } 100 \text { for further revision. }\end{array}$ \\
\hline & Symptom Checklist 90 (SCL-90) & $\begin{array}{l}\text { Severity of symptoms is } \\
\text { divided into five grades: } 1 \text { (no } \\
\text { symptom)-5 (rather severe) }\end{array}$ \\
\hline & Self-Rating Anxiety Scale (SAS) & $\begin{array}{l}\text { Delimitation value of SAS is } \\
50 \text { points. } \geq 70 \text { indicates } \\
\text { severe anxiety, } 60-69 \\
\text { moderate anxiety, } 50-59 \text { mild } \\
\text { anxiety, and } \leq 50 \text { no symptom. }\end{array}$ \\
\hline & $\begin{array}{l}\text { State-Trait Anxiety Inventory } \\
\text { (STAI) }\end{array}$ & $\begin{array}{l}\text { STAI is divided into four } \\
\text { dimensions: anger, } \\
\text { depression, vigor and fatigue. } \\
\text { Each question has a score of } \\
1-5 . \text { In each dimension, the } \\
\text { higher the score, the severer } \\
\text { the emotion of respondents. }\end{array}$ \\
\hline & Hamilton Anxiety Scale (HAMA) & $\begin{array}{l}\text { All the items of HAMA have a } \\
\text { score of five grades among } \\
0-4.0 \text { represents no symptom, } \\
1 \text { mild, } 2 \text { moderate, } 3 \text { severe } \\
\text { and } 4 \text { rather severe. }\end{array}$ \\
\hline & $\begin{array}{l}\text { Self-reporting of sub health status } \\
\text { (SRSHS)) }\end{array}$ & $\begin{array}{l}\text { For rating, } \geq 70 \text { points means } \\
\text { disease status, } 30-39 \text { points } \\
\text { health status and } 40-69 \text { points } \\
\text { sub-health status. }\end{array}$ \\
\hline & $\begin{array}{l}\text { Positive and Negative Affect Scale } \\
\text { (PANAS) }\end{array}$ & $\begin{array}{l}\text { PANAS consists of two } \\
\text { sub-scales, Positive Affect } \\
\text { (PA) and Negative Affect } \\
\text { (NA). Each of the two } \\
\text { sub-scales includes } 10 \text { items } \\
\text { describing emotions with a } \\
\text { 5-grade score (from } 1=\text { none } \\
\text { to } 5=\text { very strong). }\end{array}$ \\
\hline & Mood change diagram & $\begin{array}{l}\text { There are } 5 \text { expressions in } \\
\text { total to reflect subjective } \\
\text { feelings. }\end{array}$ \\
\hline \multirow{2}{*}{ Objective evaluation } & EEG change & $\begin{array}{l}\text { A wave is mostly adopted to } \\
\text { reflect awake and relaxed } \\
\text { state of human brain. }\end{array}$ \\
\hline & $\begin{array}{l}\text { Change with heart rate, } \\
\text { respiratory rate and skin } \\
\text { conductance responses }\end{array}$ & $\begin{array}{l}\text { Physiological indices usually } \\
\text { can indicate } \\
\text { psychological status. }\end{array}$ \\
\hline
\end{tabular}

\section{Prospects}

China's economic and social development has entered a brand-new stage at present, which is fundamentally different from the previous stage of food and clothing problem. At this stage, people are showing great interest in pursuing health and a better life; and they not only pay attention to medical treatment and health, but also hope to achieve health re- 
covery through travel, vacation and other leisure ways, so as to cope with the intense urban pressure of work and life. Besides, China's tourism environment is quite different from the others, which has combined both natural environment and cultural factors; and in a traveling environment different from the one people always live in, the existence, creation and reconstruction of various natural environments could act on people's psychological feelings through different detailed projects, thus producing therapeutic or healing effects. In this context, this paper will put forward the following research ideas for this field mainly from the perspectives of tourism and geography, in order to make the researchers more deeply aware of the various roles, complexity and spatial differentiation between natural environment and mental health. Meanwhile, we hope that it will offer some reasonable insights into form a more characteristic research direction in the future, to support the deepening, China's Ecological Civilization and the building of a Beautiful China.

\subsection{Learn from the Overseas Experience in This Field}

It's suggested to systematically summarize the international research on the relationship between natural environment and mental health, mainly regarding its development background, development process and research subjects. We should also study the corresponding relationship between natural environment and mental health as well as their periodical characteristics in other countries. In addition, the basic influencing factors, influencing mechanism, and regulatory measures for natural environment affecting mental health in foreign countries need to be summarized. Finally, it's necessary to discuss the current status and main problems in this field in China in comparison with the international research, to get a full picture clearly in the area.

\subsection{Identify the Impact Factors of Natural Environment Influencing Mental Health}

Impact factors (namely health factors) behind the influence of natural environment on mental health should be scientifically identified. Based on the evaluation results of body comfort, the formative indicators of various natural factors (such as temperature, humidity, air quality, wind velocity) and their combination ways should be analyzed and evaluated. What's more, the comparative research on the impact of various natural landscapes and landscape graphic structure models on mental health should be enhanced, which could guide the improvement of natural environment, such as natural scenic spots and urban green space, and other ecological factors of landscape. As well, some population groups, such as children, adolescents, the middle-aged (working) people and the elderly, should be particularly considered in the future research, and certain impact factors on the population groups should be discussed.

\subsection{Establish an Evaluation System on Psychological Effect of Natural Environment}

Scientific evaluation methods need be developed in order to evaluate the mental health benefit of natural environment factors of different types. In general, an evaluation system integrating the subjective evaluation based on psychological testing and the objective evaluation based on physiological indices should be established, and meanwhile, a unified experimental tool kit including sphygmomanometer, heart rate monitor and multipurpose polygraph should be developed to ensure that the evaluation methods are scientific and the research results are comparable. Moreover, the comparative research on the psychological effects between natural and artificial ecological environment should be reinforced in the future.

\subsection{Strength the Study on the Utilization and Influencing Mechanism of Natural Environment on} Mental Health

Natural environment of multiple scales and types in the different regions need be selected for comparison. On such basis, the typical utilization modes of natural environment on mental health should be summarized, with their individual features, common features and forming reasons to be revealed at the same time. It's important to popularize the application value of natural environment, and we ought to develop such leisure products 
as forest health, forest tourism, coastal tourism, nature tourism, garden visiting as well as gardening practice. We also need to discuss the consequences of different utilization modes, along with their changing process and the interactive characteristics of various natural factors. Furthermore, efforts should be made to tap into the potential of different natural environment factors in preserving mental health, and come up with utilization modes compatible with the characteristics of the natural environment.

Author Contributions: Conceptualization, review and editing, L.Z. and H.Y.; writing-original draft preparation, D.Z. All authors have read and agreed to the published version of the manuscript.

Funding: This research was funded by the National Key R\&D Program, China, No. 2017YFC0506401 and the Second Tibetan Plateau Scientific Expedition and Research, No. 2019QZKK0401. The Strategic Priority Research Program of Chinese Academy of Sciences, No. XDA20020300.

Institutional Review Board Statement: Not applicable.

Informed Consent Statement: Not applicable.

Data Availability Statement: Not applicable.

Conflicts of Interest: The authors declare no conflict of interest.

\section{References}

1. Liu, H.S. Rethinking of the Concept and Standard of Mental Health. Psychol. Sci. 2001, 24, 479-480.

2. Liao, Y.G.; Lian, R. Changes in Chinese People's Mental Health, China from 1986 to 2017: A Cross-Temporal Meta-Analysis. J. South Univ. (Soc. Sci.) 2019, 45, 105-116.

3. Liu, S.; Cui, X.L. An Empirical Analysis of Travel and Mental Health. J. Beijing Int. Stud. Univ. 2013, 11, 79-83.

4. Chen, X.F. Research and Practice of System of Public Psychological Services. Bull. Chin. Acad. Sci. 2018, 33, 308-317.

5. Ning, W.W.; Ran, L.W.; Dong, J.; Feng, G.; Jiang, H.B.; Wang, X.Q. The Development of Chinese Mental Health and Early Warning Scale. J. Southwest Jiaotong Univ. (Soc. Sci.) 2017, 18, 28-34.

6. Xu, Z.M.; Wu, J.P. Residential Greening Environment and the Physical and Mental Health of Residents: The Mediating Role of Life Satisfaction. Psychol. Technol. Appl. 2015, 6, 7-13.

7. Zhang, D.T. Health Benefits and Influencing Factors of Urban Green Space to Residents. Master's Thesis, Northwest Agriculture \& Forestry University, Yangling, China, 2019.

8. Zhang, J.Z. The World's Most Popular "Forest Bathing" (1). Shaanxi For. Sci. Technol. 1995, 2, 66-68.

9. Xiao, Z.X. Eco-Psychology Reviews. J. Taiyuan Univ. Technol. (Soc. Sci. Ed.) 2004, 22, 66-68.

10. He, F.Y. The Scientific Principles of Forest Bathing. Sichuan For. Explor. Des. 1999, 3, $23-25$.

11. Hu, Y.W.; Yang, J. Research Progress in Sanitarian Function of Urban Forest. J. Chin. Urban For. 2012, 10, 18-20.

12. Shu, Y.; Wu, R.W.; Shi, Y.; Ren, W.T.; Bao, Z.Y. Review of Psychological Health Research in Urban Green Space. Jiangsu Agric. Sci. 2018, 46, 8-13.

13. Wen, J.; Liu, X.X.; Huang, X.F. Research Progress in the Effect of Scenic Recreational Forest on People's Physiological and Psychological Health. J. Anhui Agric. Sci. 2012, 40, 12116-12117, 12126.

14. Wang, X.H. The Research on the Integration Model of Tourism with Stress Displacement. Master's Thesis, Southwestern University of Finance and Economics, Chengdu, China, 2009.

15. Ma, Y. The Review and Reflection of Wildness Therapy. Master's Thesis, Beijing Forestry University, Beijing, China, 2010.

16. Wang, Y.Y. Outdoor Sports and Nature Fusion Therapy for the IT Staff the Utility of Mental Health. Master's Thesis, Southwestern University of Finance and Economics, Chengdu, China, 2012.

17. Chen, X.; Wang, B.; Chen, L.Y.; Sun, C.Y. Go into Nature: Survey of Zhuhai Adolescents' Exposure to Nature and its Relationship with Mental Health. China J. Health Psychol. 2017, 25, 307-314.

18. Wang, Z.M.Q. Study on the Effect of Plant Campus Plant Color on College Students' Physical and Mental Health. Master's Thesis, Northwest Agriculture \& Forestry University, Yangling, China, 2018.

19. Liu, W.H. Influence of Different Forest Landscape Structure Space on College Students' Rehabilitation. Master's Thesis, Northwest Agriculture \& Forestry University, Yangling, China, 2019.

20. Zheng, Q.M.; Liu, J.; Zhu, Y.; Zhong, L.S. Perception on the sub-health Improvement of Tourists by Forest Healthcare Tourism. Res. Sci. 2017, 39, 1171-1181.

21. Mo, T. The Impact of Forest Healthcare Tourism on Stress Recovery. Master's Thesis, Hunan Normal University, Changsha, China, 2019.

22. Tan, S.H.; Sun, Y.W.; Shen, J.Z. Research on the Impact of Urban Park Environment on Public Health: From the Perspectives of Psychological Perception and Behaviors. Urban. Archit. 2018, 8, 24-28.

23. Han, M.C. Research on Composite Evaluation Index of Urban Forest Health Effects: A Case Study of Beijing National Forest Park. Master's Thesis, Chinese Academy of Forestry, Beijing, China, 2011. 
24. Chen, F.P.; Wang, Y.Q.; Li, H. The Exploration to the Function of the Forest Soundscape in Health Treatment. For. Econ. 2016, 9 , 95-99.

25. Qin, X.L.; Xia, G. Meta-Theoretical Analysis of Ecological Psychology. J. Changchun Univ. Technol. (Soc. Sci. Ed.) 2004, 16, 43-46.

26. Yi, F. The Definition of Ecological Psychology. Psychol. Explor. 2005, 25, 12-16.

27. Wu, J.P. Discussion on Ecopsychology. J. Beijing For. Univ. (Soc. Sci.) 2009, 8, 37-41.

28. Liu, T.; Chen, H.B. Review of Ecological Psychology Research. J. North. Univ. (Soc. Sc.) 2002, 4, 83-85.

29. Ma, B.F.; Li, W.Q.; Yang, L. The Analysis of Inhabitants' Psychological Adjustment in an Ecological Environment. J. Neijiang Norm. Univ. 2008, 23, 107-110.

30. An, Q. Review of the Research on Ecological Psychotherapy. Sci. Educ. Art. Coll. 2015, 12, 180-181.

31. Xue, J.; Wang, Q.; Fu, X.T. Forest and Health. Foreign Med. Sci. (Sect. Medgeogr.) 2004, 25, 109-112.

32. Bai, F.M. The Promoting Effect of Forest to Human Health. For. Ecol. 2018, 1, 17-19.

33. Wen, J. Study on Effect of Beijing Forest Recreational Areas on Visitors' Physiology and Psychology Health. Master's Thesis, Beijing Forestry University, Beijing, China, 2012.

34. Sun, Q.X.; Peng, Z.H.; Zhang, Q.S. Volatiles of Wood of Chinese Fir in Nature and its Effect on Human Health. J. Anhui Agric. Univ. 2004, 31, 158-163.

35. Li, H.; Li, C.Y.; Nan, H.L. Forest Healing Landscape. Lands. Archit. 2017, 5, 44-51.

36. Zhang, Y.L.; Wang, D. Research Advance in Effects of Forest Recreation on Human Health. J. Hebei For. Sci. Technol. 2016, 3, 86-90.

37. Li, X. The Physiological and Psychological Influences of Landscape Plant Colors on Human. Master's Thesis, Beijing Forestry University, Beijing, China, 2012.

38. Wu, L.H.; Liao, W.M. Health Care Function of Forestry Soundscape. Jiangxi For. Sci. Technol. 2009, 4, 31-32.

39. Zhu, Y. The Relationship between Experience of Forest Healthcare Tourism and Perception of Forest Healthcare Efficacy. Master's Thesis, Hunan Normal University, Changsha, China, 2015.

40. Deng, S.Y. Study on the Correlation of the Environment of Ornamental Bamboo Forest to Human Psychology. Master's Thesis, Sichuan Agricultural University, Chengdu, China, 2018.

41. Zhang, S.Q.; Hu, X.E.; Zhao, X.T.; Wang, G.M.; Tang, Y. A Research on Forest Mental Health Function Based on SAS. J. Cent. South Univ. For. Technol. (Soc. Sci.) 2018, 12, 77-82.

42. Li, C.Y.; Wang, C.; Xu, C.Y.; Li, J.; Qie, G.F.; Sun, Z.W.; Wang, Y.Y. Relationship between Visitors' Tour and State of Mental Health in Fuzhou National Forest Park. Urban Environ. Urban Ecol. 2009, 22, 1-4.

43. Hao, Z.Z.; Wang, C.; Xu, X.H.; Wang, Y.Y.; Zhang, X.; Duan, W.J.; Wang, Z.Y.; Jin, Y.B. Effect of Shenzhen Urban Forest Soundscape on Psychological and Physiological Changes of Human Beings. J. North. For. Univ. 2019, 34, 231-239.

44. Li, Z.H.; Huang, Y.B.; Chu, Y.H. Forest Bathing for Schizophrenia. Chin. J. Phys. Ther. 1998, $21,305$.

45. Pan, G.X. Discussion on Forest Bathing. East China For. Manag. 1992, 6, 7-9.

46. Zhang, J.Z. The World's Most Popular "Forest Bathing" (2). Shaanxi For. Sci. Technol. 1995, 3, 61-63.

47. Dan, X.Q.; Jiang, H.X.; Gong, Y. Discussion on the Planning and Design of Forest Bathing. Cen. South For. Invent. Plann. 1999, 18, 36-39.

48. Xue, Q.H.; Bao, Y.F. An Innovative Design of Mental Intervention-Based Forest and Leisure Tourism Products. J. Zhejiang For. Coll. 2010, 27, 121-125.

49. Cao, Y.F.; Sun, X.; Chen, Y.; Li, W.P.; Zeng, S.F. The Relationship between Marine Ecological Health and Physical as well as Mental Health of Population. Ocean Dev. Manag. 2013, 5, 69-72.

50. Yang, Y.H.; Huang, J.R.; Wang, J. Effect of Seaside Convalescent Factors on Mental Health Status of Retired Military Convales-cent. Chin. J. Clin. Rehabil. 2003, 7, 3758 .

51. Cui, X. The Effect of Recuperative Factors on Sub: Healthy Recuperation at Sanya Resort. J. Log. Univ. CAPF (Med. Sci.) 2012, 21, 557-558.

52. Li, S.H.; Yao, Y.N.; Liu, C.; Kang, N. The Effect and Mechanism of Greenspace on Human Physical and Mental Health: A Proposal of Green Medicine. Chin. Landsc. Archit. 2019, 35, 5-11.

53. Fang, C.; Wang, C.; Guo, E.G. Relationship between Urban Green Space and Health of Urban Residents. J. Northeast For. Univ. 2010, 38, 114-116.

54. Fang, C.; Guo, E.G.; Wang, C.; Qie, G.F.; Sun, Z.W.; Li, C.Y. Relationship between Use Frequency of Urban Green Space of Urban Residents and their Mental Health. Urban Environ. Urban Ecol. 2008, 21, 10-12.

55. Ying, J. The Research of City Green Space for the Human Healthy Influence of Body and Mind. Master's Thesis, Nanjing Agri-cultural University, Nanjing, China, 2007.

56. Xing, Z.J.; Kang, Y.X.; Li, M.D. Physiological and Psychological Influences of the Landscape Plant Form on Human. J. North. For. Univ. 2015, 30, 283-286.

57. Kang, N.; Xiu, M.L. Effects of Visual Characteristics for Different Types of Plant Community on Human Psychology. J. North. For. Univ. 2017, 32, 315-320.

58. Zhao, R.L.; Zhang, Y.L.; Wang, X. Effects of Paeonia Suffruticosa Viewing on Physiology and Psychology of University Students. Landsc. Archit. 2019, 26, 109-113.

59. Duan, Y.F. The Investigation Study on the Psychological Effect of Different Garden Plant Landscape on People. Master's Thesis, Northwest Agriculture \& Forestry University, Yangling, China, 2017. 
60. Liu, J.Z.; Han, Y.E. Advances in Research on the Regulation Mechanism of Plant Aroma on Human's Mentality. World Latest Med. Inform. 2018, 18, 93-94.

61. Pan, X.L. Anxiety Relieving Study on the Aroma of Three Kinds of Essential Oil. Master's Thesis, Shanghai Jiao Tong University, Shanghai, China, 2009.

62. Quan, M.P.; Shi, W. Function and Application in the Garden of Aromatic Plants. Northwest Hortic. 2013, 6, 86-89.

63. Wang, Q.H.; Li, H.J.; Wang, J.M. Clinical Application of Aromatherapy and Aromatic Oil. Foreign Med. Sci. (Chin. Med.) 2001, 23, 326-330.

64. Kang, N.; Li, S.H.; Li, F.H. Study on the Effect of Different Landscapes on Human Psychology. Chin. Landsc. Archit. 2008, 7, 69-72.

65. Liu, B.X.; Xu, Y. Study on the Effects of Different Landscapes on Elderly People's Body-Mind Health. Landsc. Archit. 2016, 7, 113-120.

66. Chen, X.Q.; Wu, J.P. Status quo of Horticultural Therapy. J. Beijing For. Univ. (Soc. Sci.) 2011, 10, 41-45.

67. Guo, C.; Jin, C.C.; Lei, X.Y. Horticultural Therapy on Autistic Children's Social Communication Disorder. J. Beijing For. Univ. (Soc. Sci.) 2012, 11, 20-23.

68. Jin, T.; Zheng, L.; Ai, W.; Li, M.C.; Ke, Y. Effect of Horticulture Therapy in Holistic Integrated Medicine. Chin. Agric. Sci. Bull. 2015, 31, 152-156.

69. Lin, D.Q.; Jin, H.X. The Current Status and Prospect of Horticultural Therapy. Chin. Agric. Sci. Bull. 2009, 25, $220-225$.

70. Ban, R.Y. effect of Horticultural Therapy on Patients with Chronic Schizophrenia. J. Nurs. Sci. 2001, 16, 518-520.

71. Gao, Y.; Huang, S.; Lu, Y.Q. Effect of Horticultural Therapy on Rehabilitation of Chronic Schizophrenia. China Med. Pharm. 2016, 6, 202-205.

72. Lv, M.M.; Ma, X.W. Horticultural Therapy for Patients with Schizophrenia: A Literature Review. Mod. Clin. Nurs. 2018, 17, 68-74.

73. Guo, T.H.; Dong, Q. Restoration of Children's Connection with Nature: Therapeutic Garden for Nature-Deficit Disorder. Chin. Landsc. Archit. 2015, 8, 62-66.

74. Hu, T.T.; Tang, X.M. Design for Autism: An Introduction of the Garden Court Design. J. Shanghai Jiaotong Univ. (Agric. Sci.) 2016, $34,85-89$.

75. Huang, Q.W.; Zhou, D. Effect of Horticultural Therapy to Mentality Inpatients' Anxious Mood. J. Clin. Nurs. 2012, 11, 4-6.

76. Lin, S.Y. A Study on the Intervention of Horticultural Therapy on Junior High School Students' Sense of Alienation. Master's Thesis, Hangzhou Normal University, Hangzhou, China, 2016.

77. Huang, X.X.; Ma, B.H.; Zhang, L.F. The Applied Exploration of Horticultural Therapy in Improving Mental Health of College Students Majoring in: A Case Study of Hebei Agricultural University. J. Hebei For. Sci. Technol. 2018, $14-17$.

78. Qi, H.Y.; Zhang, P.; Zhang, L.F. Research on Intervention of Horticultural Therapy on Psychological Problems of College Students. Mod. Hortic. 2019, 2, 164-165.

79. Xiu, M.L.; Li, S.H. A Preliminary Study of the Influence of Horticultural Operation Avidities on the Physical and Mental Health of the Elder. Chin. Landsc. Archit. 2006, 6, 46-49.

80. Liu, L.; Qin, H. The Application of Horticulture Therapy in the Psychological Rehabilitation of Earthquake Victims. J. South. Agric. Univ. (Soc. Sci. Ed.) 2010, 8, 229-231.

81. Ma, B.J. Essence and Behavior Characteristics of Nature-Tourism from Viewpoint of Biogenetic. J. Beijing For. Univ. (Soc. Sci.) 2010, 9, 65-67.

82. Li, X.H.; Zhou, L.; Liu, B.H. Exercise and Fitness Tourism and Rehabilitation of Sub-Health. Chin. J. Health Educ. 2004, 20, 145-146.

83. Xiang, X.X. Research of Tourism Activities' Effect on the Students' Mental Health in Wenzhou Vocational College of Science and Technology. Master's Thesis, Guangxi Normal University, Nanning, China, 2015.

84. Peng, L.L. Experimental Study of Recreation Sports Tourism' Effect on Easing Front-Line Workers' Pressure on Railway. Master's Thesis, Yangzhou University, Yangzhou, China, 2012.

85. Yan, F. Effects of Tourism Activities on the Human Spiritual Life. Master's Thesis, East China University of Science and Tech-nology, Shanghai, China, 2014.

86. Wang, H.Y. Research on Leisure-Fitness Tourism and Sub-health Rehabilitation. J. Baoji Univ. Arts Sci. (Nat. Sci.) 2017, 37, 93-96.

87. Zhang, X.H. Thinking about the Development of Psychological Tourism. China Bus. Trad. 2012, 17, 137-138.

88. Wang, X.L.; Gong, T.T. Application of Mental Tourism in Psychological Crisis: Intervention Among High School Students. Guid. Sci. Educ. 2011, 233-234.

89. Beyer, K.M.; Kaltenbach, A.; Szabo, A.; Bogar, S.; Nieto, F.J.; Malecki, K. Exposure to Neighborhood Green Space and Mental Health: Evidence from the Survey of the Health of Wisconsin. Int. J. Environ. Res. Public Health 2014, 11, 3453-3472. [CrossRef]

90. Choe, E.Y.; Jorgensen, A.; Sheffield, D. Does a Natural Environment Enhance the Effectiveness of Mindfulness-Based Stress Reduction (MBSR)? Examining the Mental Health and Wellbeing, and Nature Connectedness Benefits. Landsc. Urban Plan. 2020, 202, 103886. [CrossRef]

91. De Bell, S.; White, M.P.; Griffiths, A.; Darlow, A.; Taylor, T.; Wheeler, B.W.; Lovell, R. Spending Time in the Garden is Positively Associated with Health and Wellbeing: Results from a National Survey in England. Landsc. Urban Plan. 2020, $200,103836$. [CrossRef]

92. Maas, J.; E Van Dillen, S.M.; Verheij, R.A.; Groenewegen, P. Social Contacts as a Possible Mechanism behind the Relation between Green Space and Health. Health Place 2009, 15, 586-595. [CrossRef] [PubMed] 
93. Hartig, T.; Mitchell, R.; De Vries, S.; Frumkin, H. Nature and Health. Annu. Rev. Public Health 2014, 35, 207-228. [CrossRef] [PubMed]

94. Kaplan, S. The Restorative Benefits of Nature: Toward an Integrative Framework. J. Environ. Psychol. 1995, 15, 169-182. [CrossRef]

95. Jarvis, I.; Koehoorn, M.; Gergel, S.E.; Bosch, M.V.D. Different Types of Urban Natural Environments Influence Various Dimensions of Self-Reported Health. Environ. Res. 2020, 186, 109614. [CrossRef] [PubMed]

96. Subiza-Pérez, M.; Vozmediano, L.; Juan, C.S. Green and Blue Settings as Providers of Mental Health Ecosystem Services: Comparing Urban Beaches and Parks and Building a Predictive Model of Psychological Restoration. Landsc. Urban Plan. 2020, 204, 103926. [CrossRef]

97. Engemann, K.; Svenning, J.C.; Arge, L.; Brandt, J.; Erikstrup, C.; Geels, C.; Hertel, O.; Mortensen, P.B.; Plana-Ripoll, O.; Tsirogiannis, C.; et al. Associations between Growing up in Natural Environments and sub-sequent Psychiatric Disorders in Denmark. Environ. Res. 2020, 188, 1-9. [CrossRef]

98. Windhorst, E.; Williams, A. "It's like a Different World": Natural Places, Post-Secondary Students, and Mental Health. Health Place 2020, 34, 241-250. [CrossRef]

99. Ulrich, R.S.; Simons, R.F.; Losito, B.D.; Fiorito, E.; Miles, M.A.; Zelson, M. Stress Recovery During Exposure to Natural and Urban Environments. J. Environ. Psychol. 1991, 11, 201-230. [CrossRef]

100. Markevych, I.; Schoierer, J.; Lupp, G.; Richardson, E.A.; Astell-Burt, T.; Dimitrova, D.; Feng, X.; Sadeh, M.; Standl, M.; Heinrich, J.; et al. Exploring Pathways Linking Greenspace to Health: Theoretical and Methodological Guidance. Environ. Res. 2017, 158, 301-317. [CrossRef]

101. Milligan, C.; Bingley, A.F. Restorative Places or Scary Spaces? The Impact of Woodland on the Mental Well-Being of Young Adults. Health Place 2007, 13, 799-811. [CrossRef]

102. Morfeld, M.; Petersen, C.; Krüger-Bödeker, A.; Von Mackensen, S.; Bullinger, M. The Assessment of Mood at Workplace Psychometric Analyses of the Revised Profile of Mood States (POMS) Questionnaire. GMS Psycho-Social-Medicine 2007, 4, 1-9.

103. Martyn, P.; Brymer, E. The Relationship between Nature Relatedness and Anxiety. J. Health Psychol. 2014, 21, 1436-1445. [CrossRef]

104. Marselle, M.R.; Irvine, K.; Warber, S.L. Walking for Well-Being: Are Group Walks in Certain Types of Natural Environments Better for Well-Being than Group Walks in Urban Environments? Int. J. Environ. Res. Public Health 2013, 10, 5603-5628. [CrossRef]

105. Bakolis, I.; Hammoud, R.; Smythe, M.; Gibbons, J.; Davidson, N.; Tognin, S.; Mechelli, A. Urban Mind: Using Smartphone Technologies to Investigate the Impact of Nature on Mental Well-Being in Real Time. Bioscience 2018, 68, 134-145. [CrossRef] [PubMed]

106. Preuß, M.; Nieuwenhuijsen, M.; Márquez, S.; Cirach, M.; Dadvand, P.; Triguero-Mas, M.; Gidlow, C.; Grazuleviciene, R.; Kruize, H.; Zijlema, W. Low Childhood Nature Exposure is Associated with Worse Mental Health in Adulthood. Int. J. Environ. Res. Public Health 2019, 16, 1809. [CrossRef]

107. Qie, G.F.; Fang, C.; Wang, C.; Li, C.Y. Review on Forest Physiological and Psychological Healthcare. World For. Res. 2011, 24, 37-41.

108. Ochiai, H.; Song, C.; Jo, H.; Oishi, M.; Imai, M.; Miyazaki, Y. Relaxing Effect Induced by Forest Sound in Patients with Gambling Disorder. Sustainability 2020, 12, 5969. [CrossRef] 